\title{
SYSTEMIC APPROACH TO THE CHOICE OF OPTIMUM VARIANT OF RADIOACTIVE WASTE MANAGEMENT ${ }^{1}$
}

\author{
Jaroslava Halova \\ Academy of Sciences of The Czech Republic, \\ Institute of Inorganic Chemistry, \\ 25068 Rez near Prague - Czech Republic \\ halova@ii.cas.cz \\ Tomas Feglar \\ I2S a.s. - Information Integrity Services \\ Vinohradska 184, 15000 Praha 3 - Czech Republic \\ feglar@i2s.cz
}

Keywords: Expert Choice 2000, radioactive wastes

Summary: Czech Republic started its research in the area of nuclear safety in the 50's. Attention was paid mainly to the technological criteria and to the simulation of technological systems, including radioactive waste management. In 1982 the Analytical Hierarchy Process (AHP) was applied to radwaste management criteria for the first time in the limited range and without consistency checking. Nuclear safety including radwaste management became hot topics in connection to the new Czech nuclear power plant-Temelin. It was the right time for AHP research comeback. Firstly we repeated the original project, then we improved inconsistency of the original results and finally we performed new research based on the newly designed multicriterial space. All these steps were realized as one AHP project. This approach enabled simulation and comparison of two decisions: one from the 1980's framework, the second one in the 2000's framework.

\section{Introduction}

Our real world is full of heterogeneous interconnected problems. This situation is not new. This is the reason for mathematical theory of multicriterial decision (Keeny and Raiffa, 1976; Saaty, 1980).

Czech Republic should be ready for situations when final decision is subjected to a sharp criticism even on the international level.

Czech experts have the world priority in the multicriterial evaluation of variants of the management of radioactive waste from nuclear power plants as early as in 1982 (Halova, Gluckaufova, and Kunclova, 1985; Gluckaufova, Halova, and Marek, 1985),

The problems of nuclear safety of NPPs are of topical interest in our country today. That is why we decided to analyze the results published in the 1980's using new knowledge and software. We focused our attention on the unpublished aspects or on the results published without accuracy assessment. Finally

1 This work as a whole could be realized only thanks to the understanding of Professor Thomas L. Saaty and to kind help of Mr. James Orris, who generously allowed the use of Expert Choice 2000 software which has been proven as an excellent analytical tool. 
we tried to modify the set of multiple criteria from the point of view of present possibilities. This approach enabled the comparison of the results published in 1982 to our results.

There are various approaches to the management of radwaste nuclear power plants. Researchers or managers start their work with a choice. The choice can be realized as a comparison of existing technological systems or it can be based on the generation of reasonable technological systems as a combination of unit operations. Experts in 1982 used the latter possibility. It reflects purely engineering aspects and it cannot fulfill requirements, typical for heterogeneous set of the objectives.

Our new analysis was improved by a new approach. We model four hypothetical technological systems enhanced with semantic interpretation. The new interpretation enabled reconstruction of the original research and transfer of original mathematic-technological choice of optimum variant to the hierarchical multicriterial level. This last feature was especially useful for the design of quite new AHP model during AHPRA03 project.

\section{The Aim}

The aim consists of five partial tasks:

a) New analysis of criteria for the choice of optimum variant of management of radioactive wastes from nuclear power plants (NPPs)

b) Model example of analysis of variant technological systems of radwaste management

c) The assessment of subjective influence of experts based on the results of expert inquiry performed in NRI Rez in the early eighties (Gluckaufova, Halova, and Marek, 1985)

d) The proposal of new system of criteria and its application to the analysis of technological variants for the management of radioactive wastes from NPP's

e) Evaluation of problems solved beyond the scope of radwaste management.

\section{Methodological Approach}

We have decided to reach the aim in four Stages, using three AHP projects in accordance with diagrams in the Figure 1 and Figure 2.

We have gathered all accessible results of the original research of the 1980's in the Stage 1 and we have analyzed the methods used by researchers. Their approach was based on the combination of two methods - Saaty and ELECTRE III.

The Stage 2 was solved as a new AHPRA01 project. We wanted to obtain our own results and compare them with those, published in the 80 's.

The original research did not take inconsistency testing into consideration. We have made complete investigation of this problem. The AHPRA02 project, solved in the Stage 3 consisted of 10 clones, one for each expert interviewed in the 80 's.

During our research we concluded, that we need some new model, more suitable for the situation in 2000 's. that is why we have included AHPRA03 project in the Stage 4.

\section{Stage 1: The Characteristics of the Original Project from the 1980's (Diagram 1 / Figure 1)}

There are various approaches to the radwaste management from nuclear power plants. The choice can be realized as a comparison of existing technological systems or we can generate reasonable technological systems as combinations of unit operations.

The complex approach to the multicriterial choice of optimum variant of management of radwaste from NPPs was applied to the solution of the partial task DU 07 of the project SU RVT A 01159104 mentioned above. The results of the partial task DU 07 solved by Jaroslava Halova in the years 19811985 are described by the diagram 1 in the Figure 1. 


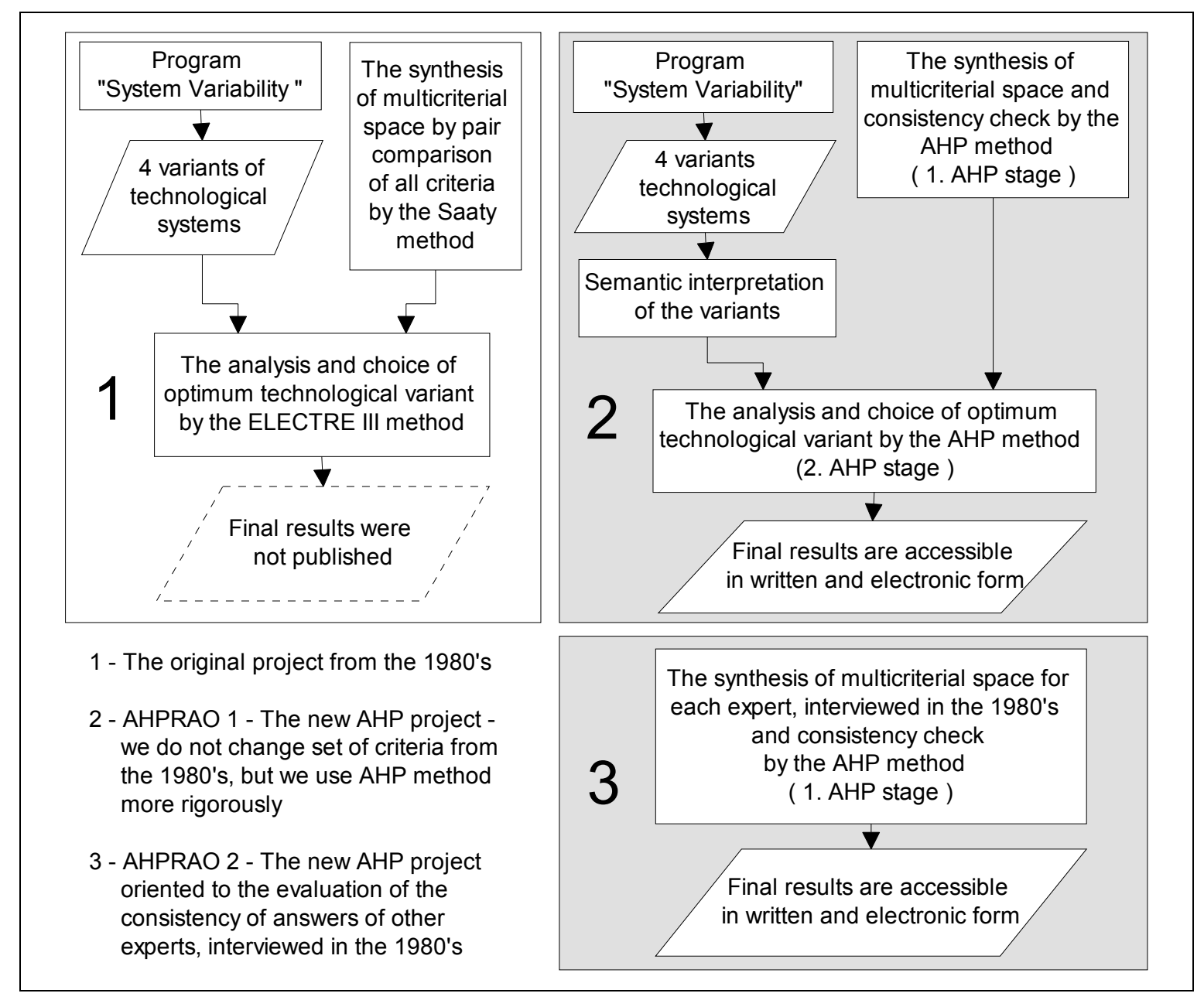

Figure 1. Project Workflow Diagram: Reconstruction of the Research in the 80's

Using the properly developed program „System Variability“ the four variants of technological systems with reasonable technological and ecological characteristics have been generated. The proposed variants were characterized by a flowchart and table of the values of activity and volume of all material flows (Figure 3).

With the aim of rational choice of optimum variant, two methods with quantitative decision of preferences of the set of characteristics were applied: Saaty method and ELECTRE III. The former was applied to the simple aggregation of characteristics, the latter as a simple preference aggregation based on sensitivity thresholds.

The Saaty method was applied to the synthesis of multicriterial space by pair comparison of all criteria. We reconstructed fully this part of the research in AHPRA01 project mentioned in the following paragraph (4a).

The ELECTRE III method was used for the analysis and choice of optimum technological variant (Halova, Gluckaufova, and Kunclova, 1985). We used AHP instead of it in the present project. We closed this investigation for the lack of final results from the eighties. 


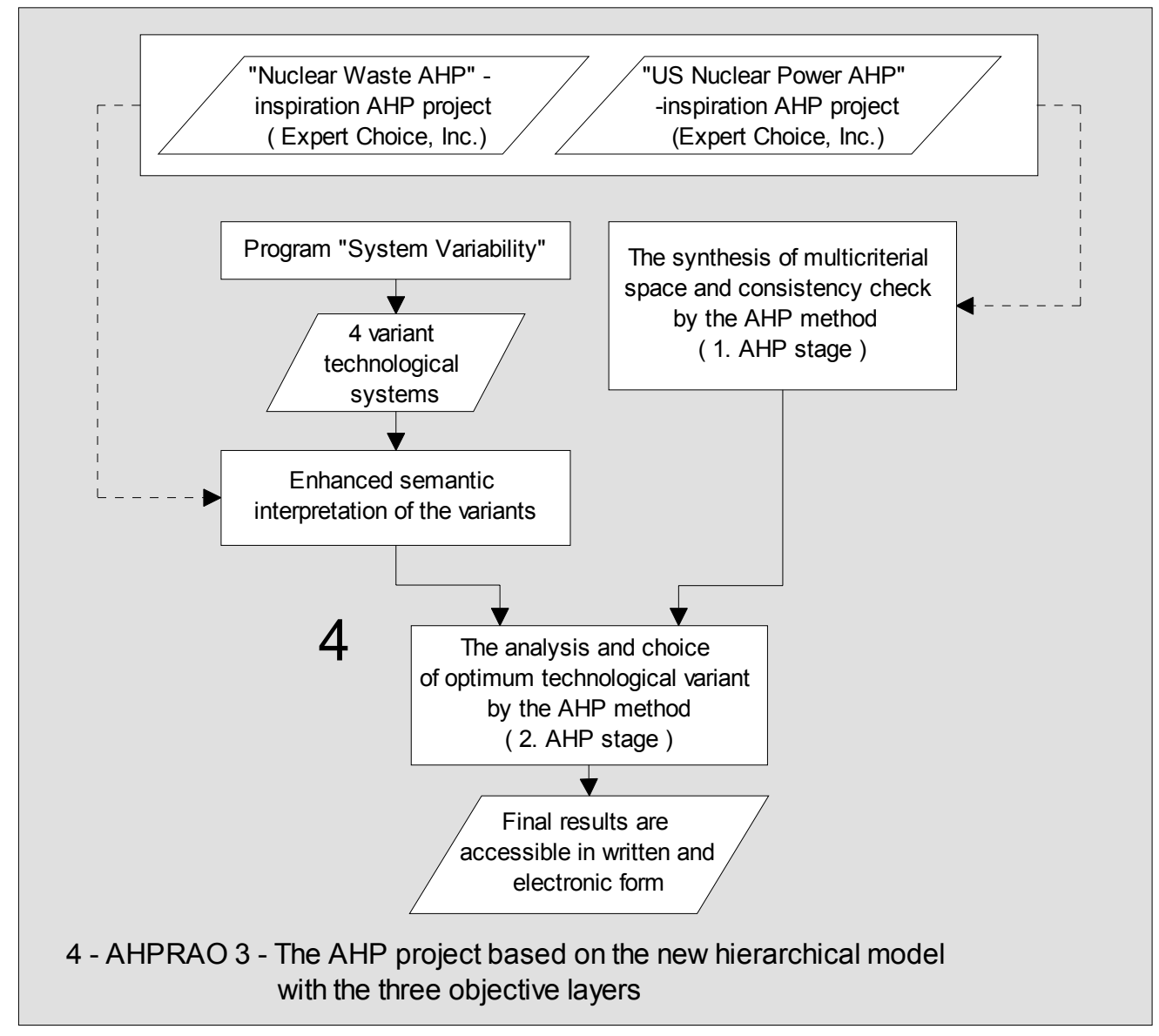

Figure 2. Project Workflow Diagram: New Research in the 2000's

\section{The Most Important Results of the Original Project from the 1980's}

\section{a) AHP Model Tree}

We designed at the beginning of the AHPRA01 project one-level model with the Goal: " Multicriterial Choice of the Management of Radioactive Wastes from Nuclear Power Plant". This model includes 11 criteria:

C1. Environmental pollution from the process of radwaste management

C2. Reliability of the technology

C3. Accessibility of the technology

C4. Product quality

C5. Volume reduction

C6. Costs of the management

C7. Complexity of technology

C8. Flexibility of technology

C9. Demands on personnel

C10. Operation time of apparatuses

C11. Decommissioning

The multicriterial AHP model tree is given in Figure 3 as a base of AHPRA01 project. 


\begin{tabular}{|l|}
\hline \multicolumn{1}{|c|}{ Model Name: AHPRAO1 } \\
Treeview \\
\hline $\begin{array}{l}\text { GOAL: The Choice of optimum variant of the Management of Radwaste } \\
\text { from NPP }\end{array}$ \\
\hline \begin{tabular}{l} 
C1: \\
manironmental pollution from the process of radwaste \\
\hline C2:
\end{tabular} \\
\hline C3: Reliability of technology (L::168) \\
\hline C4: Product quality (L:.117) \\
\hline C5: Volume reduction (L:.071) \\
\hline C6: Costs of the management (L:.028) \\
\hline C7: Complexity of technology \\
\hline C8: Flexibility of technology \\
\hline C9: Demands on personnel \\
\hline C10: Operation time of apparatuses (L:.047) \\
\hline C11: Decommissioning (L:.042) \\
\hline
\end{tabular}

Figure 3. The Multicriterial Model in the AHPRA01 Project

Over such constructed model we performed pair comparison of criteria taking into account the opinion of Expert No 1 (Prof. Leo Neumann).

\section{b) The Assessment of Experts Subjective Influence}

10 experts participated in the research in the 80's. The only judgment of the Expert No.1 was taken into consideration. The subjective influence of experts was analyzed in the AHPRA02 project. This project was oriented to the evaluation of the judgment of all experts, who participated in the research in the 80's. Each Expert has his own project clone.

Summary of our investigation is in the Table 1.

\begin{tabular}{|l|c|c|c|c|c|c|c|c|c|c|}
\hline Expert & E1 & E2 & E3 & E4 & E5 & E6 & E7 & E8 & E9 & E10 \\
\hline Inconsistency & 0,26 & 0,28 & 0,28 & 0,28 & 0,24 & 0,30 & 0,27 & 0,28 & 0,25 & 0,26 \\
\hline
\end{tabular}

Table 1. Overview of Inconsistency of Multicriterial Spaces Synthesized on the Basis of Individual Opinions of Experts

Expert 5 (0.24) had the lowest inconsistency, Expert 6 had the highest inconsistency.

We can see, that even the lowest inconsistency is higher, than the acceptable value, proven by Professor Saaty. The most serious obstacle to decrease inconsistency is too high number of pair wise compared criteria (11 instead of maximum 7, as recommended).

c) Very Low Stability of the Final Preferences

Program Expert Choice 2000 gives us highly powerful set of functions for presentation of final preferences. One of them is Performance Sensitivity graph (see graph 1 given in the Appendix). We can 
see, that the whole situation in the AHPRA01, is very unclear. Curves, describing particular variants are crossing almost in each criterion on the X-axis. Such unclear picture can cause some uncertainty or even mistakes in the final decision, as we can see in the next paragraph.

\section{d) The Quality of the Final Decision}

Synthesis of AHPRA01 analysis as a whole can be realized in accordance with two modes - Distributive (Fig 4a) and Ideal modes (Fig 4b). The position of the decision maker is not easy; there are two quite different winners.

T System 1 from the USSR is the winner in the case of Distributive mode, in comparison with the Ideal mode, when T System 3 from the U.S.A. is the best one.

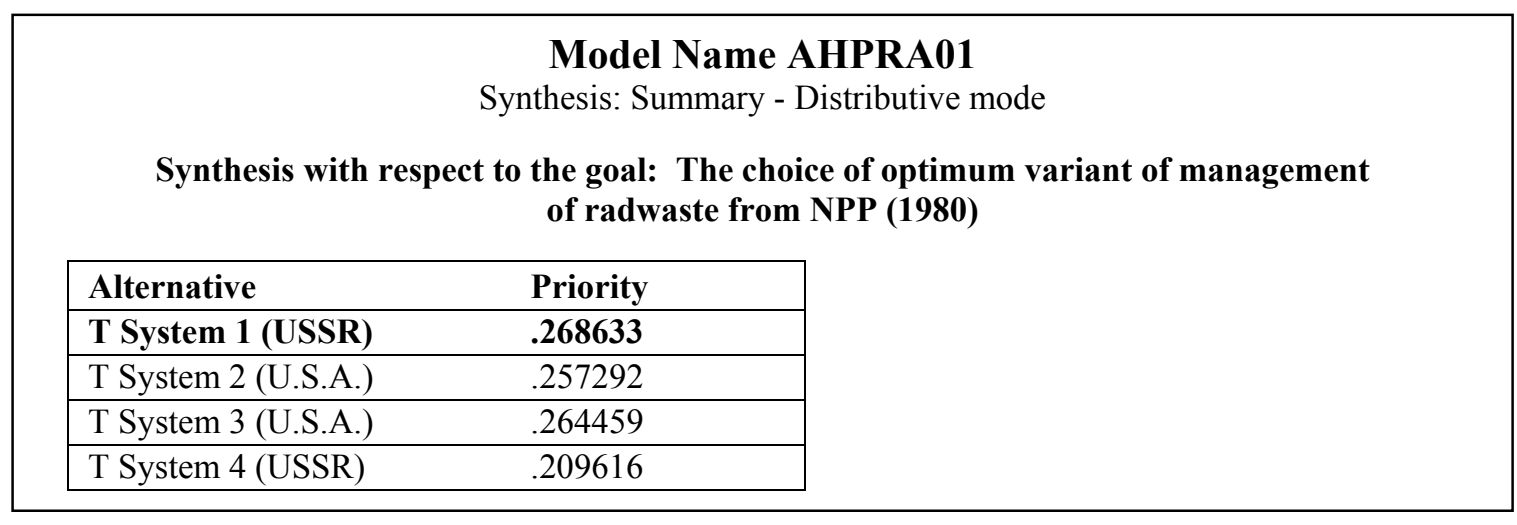

Figure 4a. Comparison of T Systems in Accordance with Criteria of 80's (Distributive Mode)

\begin{tabular}{|l|}
\hline $\begin{array}{c}\text { Model Name AHPRA01 } \\
\text { Synthesis: Summary - Ideal mode }\end{array}$ \\
Synthesis with respect to the goal: The choice of optimum variant of management \\
of radwaste from NPP (1980)
\end{tabular}

Figure 4b. Comparison of T Systems in Accordance with Criteria of 80's (Ideal Mode)

\section{The Hypothetical Technological Systems with Semantic Interpretation}

We constructed our hypothetical models in two steps.

In the first step we reconstructed the hypothetical model of technological variants reflecting the situation in the 80 's. The resulting model is described in the Table 2. Criteria, taken into consideration in the model were $\mathrm{C} 1, \ldots \mathrm{C} 11$ as described in the paragraph $4 \mathrm{a}$. In the second step we built quite a new hypothetical model. It was based on the multicriteria spaces, synthesized on the basis of individual opinion of experts. It reflects broadly the situation in 2000. The resulting model was described in four tables (for all criteria ( $\mathrm{C} 1, \mathrm{C} 2, \mathrm{C} 3, \mathrm{C} 4)$, one table per one criterion). One of them is the Table 3 . The relevant AHP model tree is in the Figure 5.

The quantities in the tables are verbal. Nevertheless, some of them are based on calculations (e.g. product quality takes into account activity and leach ability of produced radioactive waste etc). Beside the verbal 
evaluation, numerical weights are given in parentheses. The span of values reports the scale proposed for AHP applications (see Saaty, 2000, p. 73, Table 3.1).

Table 2. Model Semantic Interpretation of Technological Variants Reflecting the Situation in the 80's

T System 1: Top technology, reflecting in the 80 's in the USSR.

T System 2: Average technology, reflecting in the 80 's in the U.S.A..

T System 3: Top technology, reflecting in the 80 's in the U.S.A.

T System 4: Average technology, reflecting in the 80's in the USSR.

\begin{tabular}{|l|ll|ll|ll|ll|}
\hline & T System 1 & & T System 2 & & T System 3 & & T System 4 & \\
\hline C1 & Very low & $(7)$ & Very low & $(7)$ & Very low & $(7)$ & Low & $(5)$ \\
\hline C2 & Average & $(5)$ & Very good & $(6)$ & Excellent & $(8)$ & Average & $(5)$ \\
\hline C3 & Very good & $(7)$ & Bad & $(5)$ & Very bad & $(3)$ & Excellent & $(9)$ \\
\hline C4 & Very good & $(5)$ & Very good & $(5)$ & Excellent & $(7)$ & Very good & $(5)$ \\
\hline C6 & Low & $(7)$ & Average & $(5)$ & Better-than-average & $(3)$ & Very low & $(9)$ \\
\hline C10 & Average & $(4)$ & High & $(6)$ & Very high & $(8)$ & Low & $(2)$ \\
\hline C11 & Average & $(4)$ & Good & $(6)$ & Very good & $(8)$ & Average & $(4)$ \\
\hline
\end{tabular}

Table 3. Broader Description of the Situation with Semantic Interpretation of Technological T Systems in 2000. Group of the Technological Criteria (C1)

T System 1: Top technology, reflecting in the 80 's in the USSR

T System 2: Average technology, reflecting in the 80's in the U.S.A.

T System 3: Top technology, reflecting in the 80's in the U.S.A.

T System 4: Average technology, reflecting in the 80's in USSR

\begin{tabular}{|l|l|lr|ll|ll|ll|}
\hline & & T System 1 & T System 2 & T System 3 & T System 4 & \\
\hline C1.1 & & Average & $(5)$ & Very good & $(6)$ & Excellent & $(8)$ & Average & $(6)$ \\
\hline \multirow{2}{*}{ C1.2 } & 1 & Low & $(3)$ & Low & $(3)$ & Very low & $(1)$ & Low & $(3)$ \\
\cline { 2 - 9 } & 2 & Low & $(3)$ & Low & $(3)$ & Low & $(3)$ & Low & $(3)$ \\
\hline C1.3 & & Average & $(4)$ & Average & $(4)$ & Very high & $(8)$ & Low & $(3)$ \\
\hline C1.4 & & Low & $(3)$ & Limited & $(6)$ & Good & $(5)$ & Low & $(7)$ \\
\hline
\end{tabular}

Comment:

C1.4: Compatibilities depend on combination of spare parts from Russia and the U.S.A.. Regarding economic stability we can assume higher flexibility of American firms.

\section{The Most Important Results of the 2000 Project}

a) AHP Model Tree

We designed new set of criteria, including 4 groups of criteria on the highest hierarchical level, with three level hierarchical structure in accordance with the Figure 5.

Thanks to the fact that no node of the multicriterial tree has more than 5 lower level nodes, we succeeded in fulfilling the consistency condition. The final inconsistency was lower than 0.1 for all matrices. 


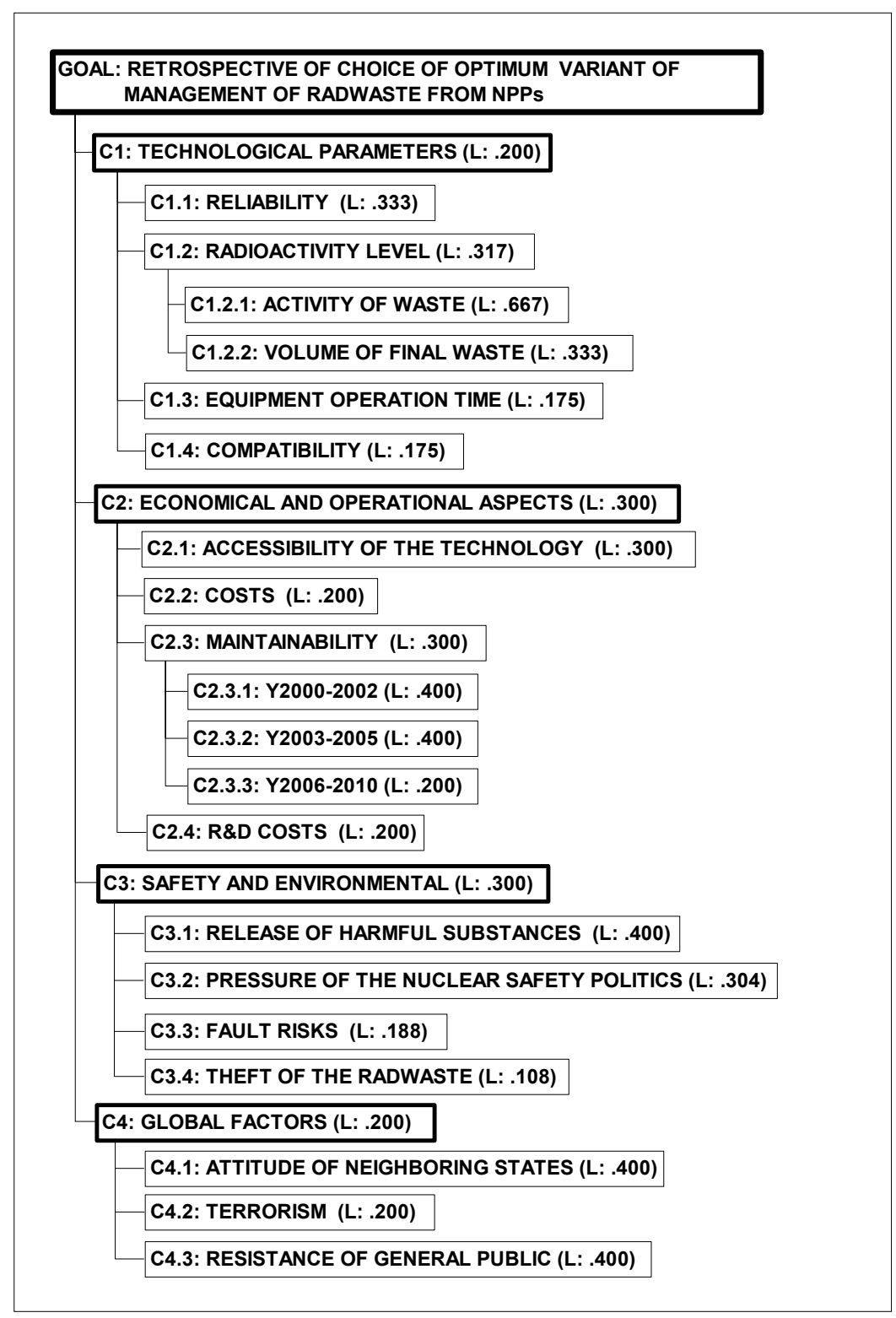

Figure 5. The Multicriterial Model in the AHPRA03 Project

\section{b) Very High Stability of the Final Preferences}

Performance Sensibility graph (see graph 2 given in the Appendix) shows the hole situation, substantially different from the situation in the 80 's (see Graph 1). Curves, describing particular variants are clearly separated. We can drill down through particular criteria $\mathrm{C} 1, . . \mathrm{C} 4$, to understand the picture within one particular criterion.

\section{c) The Quality of the Final Decision}

Synthesis of AHPRA03 analysis as a whole can be realized in accordance with Distributive (Figure 6a) and Ideal (Figure 6b) nodes. The position of the decision maker is quite clear in both cases. There is only one winner, T System 3 from the U.S.A. 


\begin{tabular}{|l|}
\multicolumn{1}{c|}{$\begin{array}{c}\text { Model Name AHPRA03 } \\
\text { Synthesis: Summary - Distributive mode }\end{array}$} \\
\multicolumn{2}{|c|}{ Synthesis with respect to the goal: The choice of optimum variant of management } \\
\\
of radwaste from NPP (2000)
\end{tabular}

Figure 6a. Comparison of T Systems in Accordance with Criteria of 2000's (Distributive Mode)

\begin{tabular}{|l|}
\hline $\begin{array}{c}\text { Model Name AHPRA03 } \\
\text { Synthesis: Summary - Ideal mode }\end{array}$ \\
Synthesis with respect to the goal: The choice of optimum variant of management \\
of radwaste from NPP (2000)
\end{tabular}

Figure 6b. Comparison of T Systems in Accordance with Criteria of 2000's (Ideal Mode)

\section{Appendix}

Graph 1 (AHPRAO1) - Performance Sensitivity Graph for the Situation of the 80's

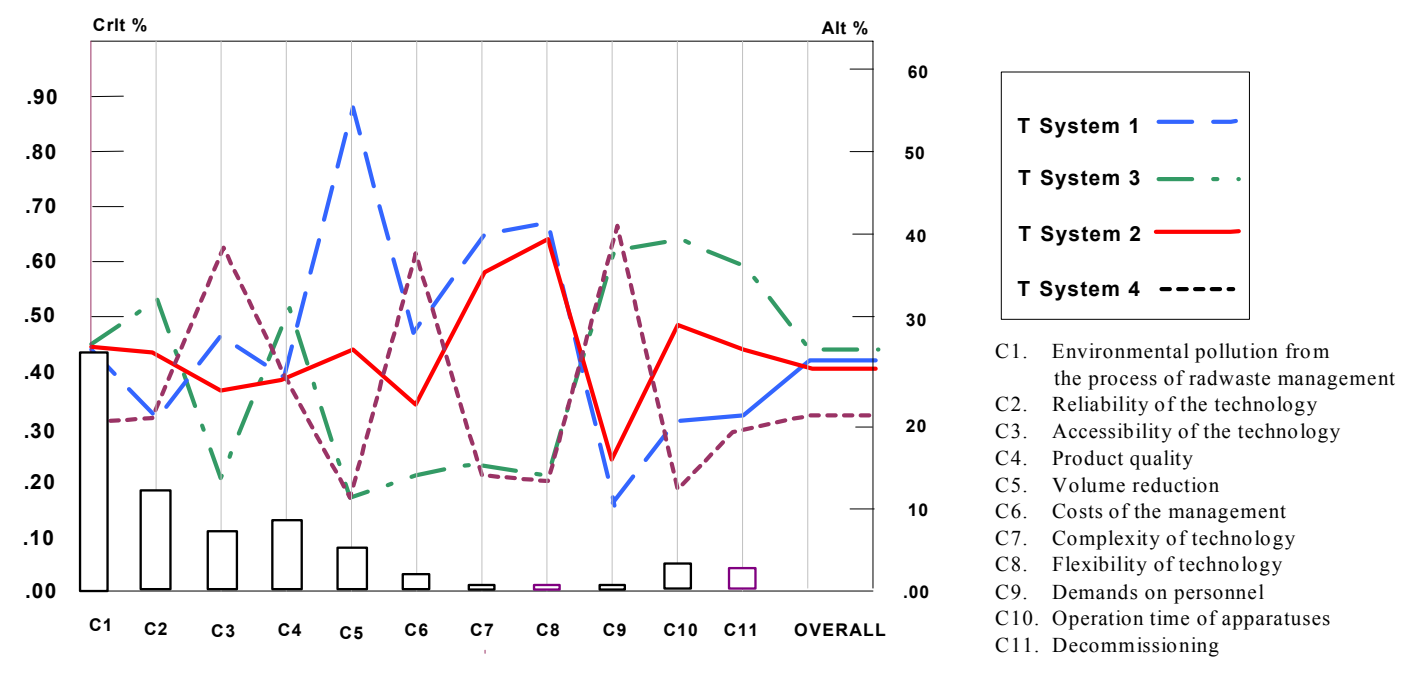




\section{Graph 2 (AHPRAO3) - Performance Sensitivity Graph for the Situation of the 2000's}

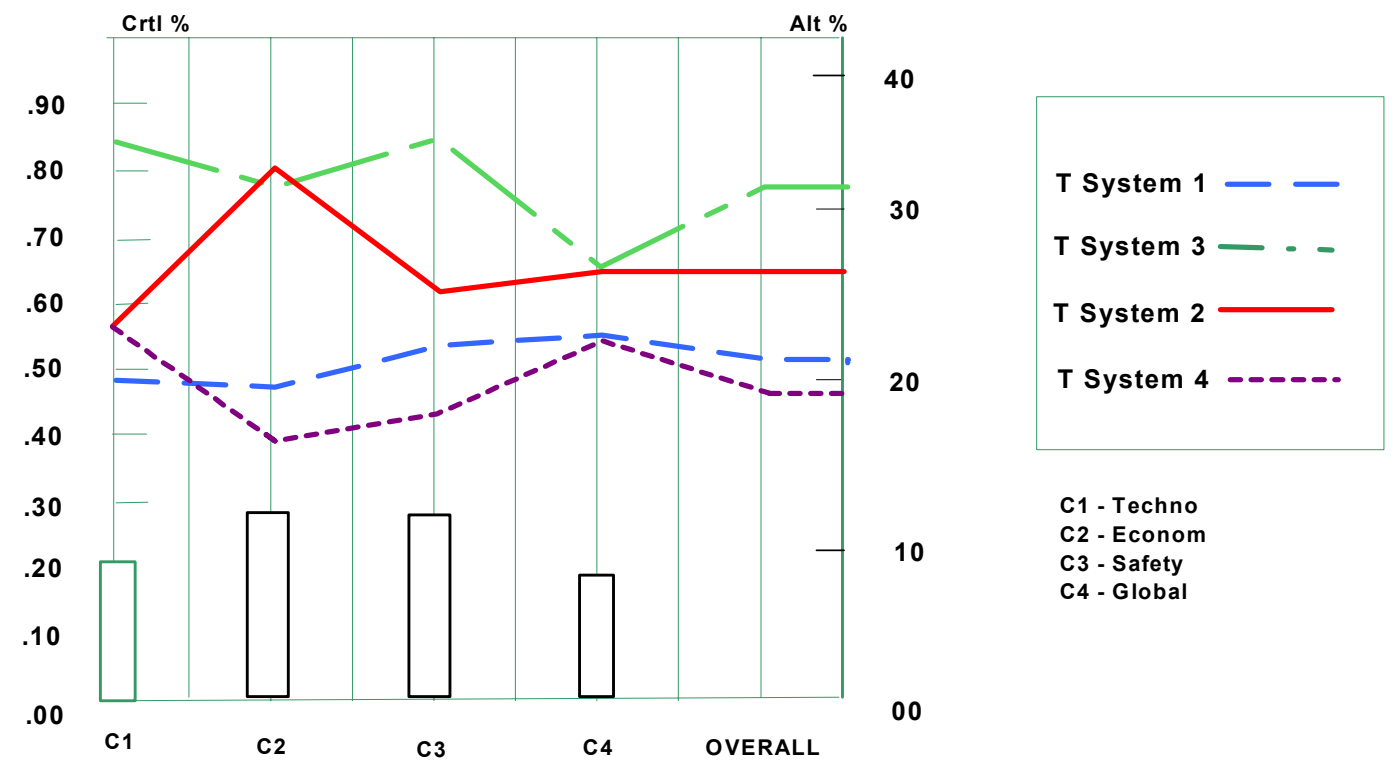

\section{References}

Keeny, R.L. and Raiffa, H. (1976), Decision with Multiple Objectives, Preferences and Value Tradeoffs, New York, John Wiley Sons.

Saaty, T. L. (1980), The Analytic Hierarchy Process, New York, McGraw-Hill, Inc..

Halova, J., Gluckaufova, D. and Kunclova, V. (1985), "The Criteria for the Choice of Variant of Management of Radwaste from NPPs", Proceeding of the Conference Management of Radwaste from NPPs with Light Water Reactors, 2, 397 - 402 (In Czech).

Gluckaufova, D., Halova, J. and Marek, J. (1985), "Complex Approach to the Analysis of Variants of Radwaste Management", Proceeding of the Conference Management of Radwaste from NPPs with Light Water Reactors, 2, 403 - 413 (In Czech).

Saaty, T. L. (2000), Fundamentals of Decision Making and Priority Theory with the Analytic Hierarchy Process, RWS Publications, 4922 Ellsworth Ave., Pittsburgh, PA.

Halova, J. and Feglar, T. (2000), Systemic Approach to the Choice of Optimum Variant of Radioactive Waste Management. Research Report, I2S a.s. 